\title{
O MONTE PASCOAL, OS ÍNDIOS PATAXÓ E A LUTA PELO RECONHECIMENTO ÉTNICO
}

\author{
Maria Rosário de Carvalho*
}

\begin{abstract}
O artigo trata do embate travado entre os Índios Pataxó e o Estado brasileiro pela posse do Parque Nacional do Monte Pascoal, para o que são utilizados a noção de eventos críticos e o modelo de conflito que atribui o surgimento e o curso das lutas sociais às experiências morais dos grupos sociais em face da denegação do reconhecimento. O objetivo é, mediante a apresentação das várias etapas do embate, demonstrar que os eventos críticos relacionados à criação do PNMP ao tempo em que ensejam graves contradições para os Pataxó, colaboram para a gênese de uma nova comunidade político-moral. O foco incide, pois, na interface demografia e antropologia, buscando relacionar as condições de vida, o deslocamento espacial e os direitos de um povo indígena.

PALAVRAS-CHAVE: Pataxó, nação, reconhecimento, luta, monumento.
\end{abstract}

No período compreendido entre 1937 e1945, como é sabido, o Brasil viveu um regime de exceção, o Estado Novo, articulado e chefiado pelo presidente Getúlio Vargas, com o apoio dos chefes militares. A Constituição de 1937, decretada pelo Presidente da República para assegurar unidade à nação - tendo em vista o que era caracterizado como perturbação da paz política e social pela crescente agravação dos dissídios partidários e o estado de apreensão criado, no país, pela infiltração comunista $^{1}$-, atribuía ao Estado um papel equivalente

* Doutora em Antropologia Social. Professora do Departamento de Antropologia e Etnologia da Universidade Federal da Bahia (UFBA). Professora Permanente do Programa de Pós-Graduação em Antropologia (PPGA) e do Programa Multidisciplinar em Estudos Etnicos e Africanos (POSAFRO) da UFBA. Bolsista PQ do CNPq.

Estrada de São Lázaro, 197. Cep: 40210-030 Federação Salvador, BA - Brasil. rosario@ufba.br

${ }^{1}$ Para situar o leitor acerca da posição comunista, no período considerado, na América Latina e no Brasil, em relação aos povos indígenas, vale lembrar que o tema só compôs a sua agenda por ocasião da consolidação do Secretariado Latino-Americano da Internacional Comunista. Na I Conferência dos Partidos Comunistas da América Latina, realizada na Argentina, em 1929, o assunto foi tratado oficialmente, através de um documento inicial para debate, elaborado pelo peruano José Carlos Mariátegui em atendimento a uma solicitação de Vitório Codovilla, dirigente do PC argentino e da IC (Cf. Buonicore, 2009). Intitulado "O problema das raças", o ao de institucionalizador da vida cultural, mediante projetos que visavam a inculcar, massivamente, conteúdos nacionalistas. O projeto orfeônico villalobiano, entre outros de igual ou menor expressão, teve, nesse sentido, "uma importante função político-educacional para um país que buscava afirmação enquanto nação" (Monti, 2007, p.14). Similarmente ao registrado em outros contextos históricos, o nacionalismo que se buscava promover obliterou as culturas preexistentes, como o fez com a cultura Pataxó (Hobsbawm, 1990). texto de Mariátegui manifesta confiança no potencial revolucionário do campesinato indígena (Ferreira, 2009). Uma síntese da conclusão do debate, apresentada por Humbert Droz, da Comissão Executiva da Internacional Comunista para a América Latina, reduziu o "problema nacional” aos Índios, especialmente aos estabelecidos no Brasil, cujas diversas línguas, costumes e tradições autorizavam tratá-los, simultaneamente, como uma raça e muitas nacionalidades, ao contrário dos negros, que já haviam adquirido uma nova nacionalidade (Cf. Buonicore, 2009). Alguns meses depois da I Conferência, a direção do PC do Brasil enviou uma contribuição ao debate, assinada por Abaeté Silva, na qual, além de criticar o processo de contato dos índios com a sociedade capitalista, afirmava que o Partido Comunista do Brasil deveria conferir atenção ao problema (La Correspondencia Sudamericana In: Buonicore, 2009). A primeira Conferência Nacional do PC do Brasil, realizada em 1934, se comprometeu a apoiar os Índios no Brasil, a se constituírem como nacionalidades, com território, governo e costumes próprios, posição defendida pelos comunistas nas assembleias constituintes de 1934 e 1945 (Buonicore, 2009). 
Através do seu Art.134, a Carta Magna atribuía à Nação, Estados e Municípios a proteção e os cuidados especiais com os monumentos históricos, artísticos e naturais, paisagens ou locais particularmente dotados pela natureza.

Em janeiro de 1938, Vargas deu início às consultas para a escolha do interventor federal na Bahia, que deveria ser baiano e civil. Após examinar vários nomes, ele se fixou no do engenheiro agrônomo e zootécnico Landulfo Alves de Almeida, que foi interventor durante quatro anos e sete meses (Tavares, 2001). O extremo-sul baiano, região de estabelecimento dos Pataxó, será alvo da atenção do seu governo através da construção de um porto, cuja fonte de recursos provinha, em grande parte, da cobrança de impostos sobre madeiras (Manuscritos - $\mathrm{Ms}^{(1)}$ e da criação do Parque Nacional do Monte Pascoal, cujo decreto previa

o completo levantamento topográfico do Monte Pascoal, sua exata situação geográfica, bem como traçados que mais diretamente o [ligassem] às cidades de Porto Seguro e Santa Cruz Cabrália (Bahia, 1941).

A primeira medida oficial com vistas à sua implantação foi a constituição de uma comissão de levantamento topográfico, através do mesmo decreto $\left(\mathrm{Ms}^{(2)}\right)$.

O Diário Oficial do Estado da Bahia de 19 de abril de 1943 publica o Decreto-Lei n ${ }^{\circ} 12.729$ que cria o Parque Nacional do Monte Pascoal (PNMP), com prerrogativa de monumento nacional, com os objetivos precípuos de rememorar o fato histórico do descobrimento do Brasil, preservar a flora e fauna típicas da região, segundo normas científicas, conservar as belezas naturais e promover a organização de serviços e atrativos que possam desenvolver o turismo. De acordo com o seu Art.3, ficava reservada, para a constituição do PNMP, uma área delimitada em relação ao Monte Pascoal, enquanto o Art. $4^{\circ}$ autorizava o governo do Estado a desapropriar, quando necessário, as terras e benfeitorias pertencentes a terceiros, incluídas na área demarcada (Bahia, 1943).

Não há, ao longo dos trâmites, qualquer referência à presença, na área delimitada, de Índios
Pataxó, que a esquadrilha do descobrimento, liderada pelo almirante Gago Coutinho, havia registrado e divulgado, em 1940, portanto em época muito recente à da criação do PNMP (Castro, 1940). A inexistência de referência não decorreria, portanto, de desconhecimento ou de qualquer dificuldade de localização, mas de um deliberado não-reconhecimento, que eu suponho relacionado ao projeto de constituição da identidade nacional do Estado Novo, cuja valorização incidia sobre o nacional, em detrimento das expressões étnicas, de autóctones, ou de imigrantes.

Os Pataxó, é importante observar, têm a sua presença registrada entre o Rio de Porto Seguro e a margem norte do São Mateus, no atual estado do Espírito Santo, desde o século XVII (Vasconcelos, 1864), ao passo que o seu estabelecimento no entorno do Monte Pascoal é referido por Luis dos Santos Vilhena, na segunda metade do século XVIII, ao assinalar a necessidade de conservação e aumento da Vila do Prado

não só pela produção de seu fertilíssimo terreno, como por poder servir de barreira, e obstáculo a 12 aldeias de índios bravos, que na distancia de 12 léguas dela, se acham situadas em uma alta serra conhecida por todos pelo Monte Pascoal, que segundo as notícias, e informações, é o centro da habitação destes bárbaros, que infestam toda a grande comarca de Porto Seguro (Vilhena, 1969, p.535).

Essa descoberta é atribuída ao capitão-mor João Domingos Monteiro.

Vilhena será complementado pelo padre jesuíta Cypriano Lobato Mendes, que atuou em uma das Missões de Índios, não-identificada, da comarca de Porto Seguro, e enviou, em julho de 1788, uma representação a D. Pedro II, na qual reclama maior atenção para a comarca, que, ao seu juízo, deveria ser "a menina dos olhos dos monarcas portugueses", sendo a terra mais fértil e mais rica das que ele conhece no Brasil, um tesouro onde se encontravam as madeiras mais preciosas do país, em abundância $\left(\mathrm{Ms}^{(3)}\right)$. O seu testemunho é tanto mais relevante por afirmar serem Pataxó os Índios anteriormente referidos por Vilhena, dos quais ele ouviu referências à existência de ouro e, particu- 
larmente, a uma celebrada Lagoa Dourada, "nas visinhanças do monte Paschoal, [em cujas] fraldas he que dizem está situado nas suas aldêas o gentio Pathaxó, que saem muitas vezes à praia à pescaria de tartarugas (...)" $\left(\mathrm{Ms}^{(3)}\right)$. A lagoa mencionada continua constituindo ponto de referência importante para os Pataxó, que costumam, orgulhosamente, apontá-la aos visitantes.

Mais importante, contudo, é o próprio Monte Pascoal, ponto por excelência de referência e guia principal dos pescadores e viajantes, tanto para orientação quanto para indicação do vento. A partir do Monte são emitidos sinais que eles interpretam, com muita segurança, como me ensinaram, há muitos anos:

Os sinais é porque a gente vê [...] no monte forma uma nuvem. Então se vê aquela nuvem na cabeça do monte puxando pela parte do sul, sabemo que o vento é norte, ou lenordeste, ou norte puro, vem do norte. E se aquela nuvem tiver jogada pro lado do norte, então sabemos que o vento vem do sul [...]

Foi para mim bastante compreensível a exasperada reação de velhos pataxós, em uma reunião em que foi cogitada a sua retirada do local, ao proporem a divisão do Monte Pascoal ao meio, de forma que "uma metade ficasse para o Brasil e outra para os Pataxó". O que, para os estranhos presentes, pode ter sido entendido como mero jogo retórico, para mim se apresentou como uma síntese da disputa étnico-nacional que se instaurava.

\section{A MEDIÇÃO DO DOUTOR BARROS}

A delimitação da área para o PNMP - denominada, recorrentemente, "a medição do Doutor Barros" - constitui um evento crítico entre os Pataxó, no sentido empregado por Veena Das, ou seja, uma situação de "quebra" do cotidiano que enseja, ao grupo afetado, se confrontar com o Estado e se constituir como ator político. O Estado, ao invés de agir em benefício dos interesses dos atingidos, age, à semelhança do Estado brasileiro, no caso sob exame, como desencadeador da ação deletéria, ignorando, deliberadamente, a sua presen- ça. De todo modo, trata-se de evento que suscita o confronto entre a racionalidade burocrática e os valores e percepções das comunidades atingidas (Das, 1995).

Tais eventos são caracterizados como críticos porque compelem os atores a desenvolverem novas formas de ação, a ressemantizarem os sentidos nativos da política e a transformarem as identidades sociais, sob uma situação de violência que, todavia, tem um sentido vivificador justamente porque, ao ser compelido ao relacionamento com os aparatos burocrático e jurídico do Estado, o grupo afetado é deslocado do mundo privado e ressurge como comunidade política, moral, detentora de direitos (1995).

Entre os Pataxó, o evento crítico referido, ao tempo em que buscou destituí-los dos seus direitos históricos de habitantes tradicionais do entorno do Monte Pascoal, despertou-os, quase literalmente, para a consciência de que constituíam uma pequena parte de uma totalidade maior. Nesse sentido, esse evento equivale à sua própria gênese como comunidade política, fomentadora de uma identidade exclusiva e detentora do direito resultante da sua préexistência no território, à criação do PNMP.

Complementarmente, as tensões e os conflitos decorrentes do evento crítico serão examinados de acordo com o modelo de conflito que atribui o surgimento e o curso das lutas sociais às experiências morais dos grupos sociais em face da denegação do reconhecimento. Nessa perspectiva, o modelo de conflito não é concebido apenas como um quadro explicativo do surgimento de lutas sociais, mas também como quadro interpretativo de um processo de formação. Assim sendo,

os sentimentos de injustiça e as experiências de desrespeito, pelos quais pode começar a explicação das lutas sociais, já não entram mais no campo de visão somente como motivos de ação, mas também são estudados com vistas ao papel moral que lhes deve competir, em cada caso, no desdobramento das relações de reconhecimento (Honneth, 2003, p.265).

A primeira referência que eu registrei sobre a medição do Doutor Barros foi no final de 1976, 
quando realizava o meu primeiro trabalho de campo individual na Aldeia de Barra Velha. Ouvia-a do então cacique Rufino Vicente Ferreira, mais conhecido como Tururim, que afirmou:

O Dr. Barros (do Rio de Janeiro) disse que ia fazer essa medição pro índio, que a gente tinha direito de ficar na terra. Eles fizeram a medicão e depois dela feita foram indenizar o pessoal. [...] e lá foi o pessoal civilizado tirando, inté saiu no conhecimento nosso aí também.

A declaração de Tururim ressalta dois pontos que serão sistematicamente reiterados por todos os Pataxó que vivenciaram ou ouviram sobre o fato, ou seja, que o Dr. Barros, provavelmente para obter a sua cooperação nos trabalhos de medição, afirmou que a medição reverteria em benefício dos índios, e que o evento os retirou do isolamento em que viviam ("saiu no conhecimento").

Além de Barra Velha, havia, à época, as aldeias de Águas Belas, Pé-da-Pedra (ou Pé-do-Monte), Imbiriba e Comuruxatiba. Mediante meticuloso recenseamento, registrei a presença de 599 habitantes no que eu denominei área do PNMP, 401 dos quais residiam em Barra Velha (206 homens e 195 mulheres), enquanto 198 (109 homens e 89 mulheres) no entorno. Um segundo censo, realizado seis meses depois desse inicial, registrou uma população de 666 indivíduos (Carvalho, 1977). Sabia-se, ademais, que significativo contingente de índios estava disperso pela região.

Oito anos depois, no decorrer de uma reunião promovida pelo Ministério do Interior e FUNAI, com a participação de representantes dos Pataxó e do Instituto Brasileiro de Defesa Florestal (IBDF), Firmo Pataxó declarou, enfaticamente, que a área demarcada, em 1980, como terra indígena não correspondia à área de ocupação tradicional, e lembrou que, por volta de 1935, “o Dr. Barros e o Dr. Marcelo mediram área para o grupo, cujos marcos encontram-se fincados, até hoje” (MINTER/ FUNAI, 1984).

Ao longo do período em que atuei como coordenadora do Grupo de Trabalho criado pela FUNAI para proceder à revisão dos limites da Terra Indígena Barra Velha e à identificação e delimi- tação da Terra Indígena Corumbauzinho (respectivamente Portarias $\mathrm{n}^{0} .685$ de 18.08 .99 e $1.262 /$ PRES/2000), ouvi de diferentes informantes constantes menções à medição, persistindo um núcleo narrativo básico, invariável, e pequenos detalhes e datas que variavam conforme o narrador. Chico Cunha, por exemplo, um octogenário, lembrava, com impressionante riqueza de detalhes para um garoto de 13 ou 14 anos, à época, que um indivíduo chamado Zé Francisco acompanhava o Dr. Barros e transportava “o aparelho” (provavelmente um instrumento equivalente a uma luneta estadimétrica), descrito como uma espécie de espelho.

Eu tava, nesse tempo, na praia, em Corumbau, eu via Caraíva na ponta do Corumbau. É, pelo espelho via tudo. Tanto os daqui via os de lá, quanto os de lá via os daqui. Fachiava assim! Dr. Barros, Aurelino Costa Barros, dizia que ia fazer a medição por ordem do governo. Abarraquemos lá mesmo, até que terminaram os trabalhos. Os marcos foram feitos lá em cima. No final, dançou baile na Barra Velha, aquela dança que chamava swing. ${ }^{2}$

A equipe se apresentou, inicialmente, como enviada por Getúlio Vargas para realizar uma medição para os índios. "Os índios acreditaram e trabalharam. Depois que fizeram o quadro, disseram que era para o governo. Os índios que moravam acima saíram e aqueles outros ficaram na areia branca”, completa, num misto de ironia e amargura, outro pataxó.

A principal controvérsia incide na data desses acontecimentos. Para Chico Cunha, eles transcorreram em 1935, com o que discorda Manuel Santana, para quem a data correta é 1944, durante a $2^{\mathrm{a}}$. Guerra Mundial. Ele afirma que "o exército estava em Caraíva” e que o governo estimulava a “tirar leite da mangaba para fazer borracha”. Patrício Ferreira não se lembra de datas, mas afirma, peremptoriamente, que marcos foram fincados e que eles ainda estão nos locais onde foram fixados, salvo, talvez, pelo marco do Salgado, que se comenta haver sido deslocado por um não-índio

\footnotetext{
O swing surgiu em meados dos anos vinte do século XX. A sua fusão com o jazz de Big Band deu lugar a uma música que teve grande repercussão, nos Estados Unidos e alhures, até a década de cinquenta.
} 
chamado Bidu, e que o capitão dos Pataxó era, à época, Honório Borges. Para ele, quem relata melhor esta história é Manuel de Suia, que se jactaria de conhecer marco por marco.

Na tarde do dia cinco de maio de 2001, em companhia de dois outros componentes da equipe do Grupo de Trabalho acima referido, isto é, o engenheiro agrimensor Hélcio Batista, da FUNAI, e o indigenista Eduardo Almeida, comprovei que Manuel de Suia era suficientemente capaz não apenas de rememorar os eventos relacionados à medição, mas de reatualizá-los, no terreno, com precisão e convicção. O teste empírico teve início em Caraíva, a partir das 13h 02min, sob forte sol. Suia lançou mão de uma espécie de estratégia mnemônica, isto é, rememorou oralmente os fatos, segundo a ordem da sua ocorrência:

Começamos em Caraíva. Botamos o marco em Caraíva e vimos botando outro marco, aqui embaixo, perto de Barra Velha. O marco de Barra Velha ele botou por fora, mediu por fora, pelo mar. Depois seguiu pro Farol de Corumbau. Do Farol pra Bunda da Nega, outro marco. Serra do Gaturama. Corta o rumo pro Montinho. Do Gaturama botou um marco num pé de quebrapote. Em Caraíva, no Cadinho, na Fazenda, do outro lado, e outro marco na Corrida. A Corrida fica na estrada que vai pra Monte Pascoal, acima de um morador por nome Nenê Batista. Outro marco na boca do Guaxuma, do outro lado do rio Guaxuma. O rio grande de Caraíva está aqui, e aqui é o Guaxuma, nós entrou aqui, pegou o rio do Cemitério. Aí nós subiu, foi fazer canto no Montinho.

O primeiro marco foi localizado na estrada que liga Barra Velha a Caraíva, de onde se ouve o movimento das ondas do mar. É o marco da Areia Branca, cujas coordenadas GPS são S16 50.611 ' W39 08.737' BRG 27 $7^{\circ}$ DIS 6.41/ TRK 23 /GS 01,02. O segundo marco, Marco do Ferrinho, fica à margem da lagoa de Barra Velha (S $16^{\circ} 49.539^{\prime}$ W39 $^{\circ}$ 08.841' BRG $30^{\circ}$ DIS 5.19 ${ }^{\circ}$ TRK $13^{\circ}$ GS 0.0-0.2). Construído de pedra e cimento, está bem conservado, salvo pelas extremidades que se encontram quebradas.

Às 14h 13min, alcançamos Caraíva, em demanda do marco fixado no local denominado Mangalô, propriedade da suíça Merreille Immer desde 1994, que não permitiu a entrada da equi- pe. O GPS registra, do portão da sua propriedade, $\mathrm{S} 16^{\circ} 48.217^{\prime}$ W $39^{\circ} 08.994^{\prime}$ BRG $35^{\circ}$ DIS 372 TRK $160^{\circ} \mathrm{GS}$ 0.0/0.2. Retornamos, em busca, agora, do Marco ZeBedeu, na Aldeia de Barra Velha. No local onde ele foi fixado e mais recentemente avistado por Suia, quebrado, só há um dendezeiro (S $16^{\circ} 51.340^{\prime}$ W39 $09.033^{\circ}$ BRG $29^{\circ}$ DIS 7.28 TRK $23^{\circ}$ GS 01/05). O próximo marco é Cadinho, do outro lado do rio Caraíva. Devido ao avançado da hora, interrompemos os trabalhos.

Afinal, não restava dúvida de que a memória oral pataxó havia resistido à verificação empírica, como a situação descrita bem o demonstrou. ${ }^{3}$

\section{Consequências da medição do Doutor Barros}

A finalização dos trabalhos de medição deve ter causado crescente inquietação à medida que os vários índios recrutados relatavam o que haviam visto, ouvido e feito, com os inevitáveis acréscimos, interpretações e conjecturas que terminavam por granjear ao narrador certa notoriedade, notadamente em face dos não-participantes ou nãotestemunhas. Eu suponho que esse evento crítico ocorreu em determinado período da década de quarenta do século vinte, talvez 1944, como o afirma Manuel Santana.

A inquietação teria dado lugar à necessidade de agir, a exemplo do que fizeram outros capitães ${ }^{4}$ que antecederam Honório Borges. Ele deve ter enfrentado uma árdua viagem, naquele longínquo agosto de 1949, juntamente com dois assistentes, Manuel Caetitu e Leôncio, e não sem temor, pois, afinal, tratava-se da sua primeira viagem para a capital da República. Do Rio de Janeiro

${ }^{3}$ A área calculada, mediante traçado de linhas retas entre os marcos, totalizou 69.898 ha.

${ }^{4}$ Ferdinand Dennis observa, a esse propósito, que "as tribos do Rio Doce e do Belmonte enviavam algumas vezes em missão ao Rio de Janeiro aqueles chefes e guerreiros que acreditavam serem os mais eloquentes: estes estranhos embaixadores revestiam-se de uma pompa insólita. Segundo o costume invariável, iam pintados de urucu e jenipapo; uma comprida pele de tamanduá servia de capa a um dentre eles. Foi sob tão singular aspecto que uma família inteira apareceu nas ruas do Rio de Janeiro ao hábil artista do qual aproveitamos seu retrato" (1980, p.237). 
alguém deve tê-lo conduzido para Niterói e redigido, em português claudicante, um dramático pedido de auxílio, com data de $1^{\circ}$ de setembro: "Do capitão Onoro para [sic] os pobres Chefe da ardea de indio de Belo Jardim Monte pasqual. Manda pedir roupa para minhas crianças e pesso feramenta para o meu trabalho faso um pedido que não deixe de atender. Peso o favor de não deixar o pessoal da India tomar minhas terras ${ }^{5}$ eles tan tando para panhar, Ardea dos Indios de Belo Jardim Monte Pascual que fica acima de porto Seguro na Bahia" (SPI, 1949, ênfases adicionadas).

A carta do capitão é objeto de uma tramitação estranhamente errática e longa. Protocolada, ela é encaminhada, em 5 de setembro de 1949, por Modesto Donatini, Diretor do SPI, ao Inspetor Especializado Alísio de Carvalho, sediado em Teófilo Otoni, Minas Gerais, e igualmente dirigida à Inspetoria Regional 4, cuja sede era Recife, onde é também protocolada e encaminhada ao Inspetor Sílvio dos Santos. Em 6 de julho de 1951, portanto um ano e dez meses depois, o processo SPI $\mathrm{n}^{0}$ 4073/49 é encaminhado ao agente Manoel Moreira Araujo "para esclarecer tendo em vista a última informação". No dia 6 do mesmo mês e ano, Araujo se dirige ao diretor Malcher, informando que "A aldeia dos índios de que faz parte o "capitão" Onório Borges, situada em Belo Jardim, no Município de Porto Seguro, Estado da Bahia, foi destroçada pela polícia de Ilhéus, sob o comando do major Arsênio Alves, encontrando-se o dito "capitão" preso incomunicável, em Ilhéus, tendo vindo escoltado de Salvador

Desde outubro de 1950, Getúlio Vargas havia sido eleito Presidente da República, tomando posse em janeiro de 1951, sob fortes boatos de golpe contra a posse, dissipados por declarações dos comandantes do exército, marinha e aeronáutica, uma correlação de forças que historiadores, a exemplo de L. H. Dias Tavares, afirmam expressar o "su-

${ }^{5}$ A expressão "pessoal da Índia" constitui eloquente demonstrativo do isolamento sociocultural em que viviam os Pataxó até essa época, limitados, em grande parte, à posição de receptores das informações oriundas de Caraíva. Ao tentar colher o significado de "pessoal da Índia”, li o trecho para o pajé Albino Braz Pataxó, em 1999, que o glosou como "pessoal de um país estrangeiro". cesso da campanha O Petróleo é Nosso”, em curso em todo o país, desde 1948 (Tavares, 2001, p.67).

Ao longo de todo esse ano, a polarização causada pelo decreto de criação da Petrobras, que Vargas enviara à Câmara Federal, assim como, notadamente, a campanha contra o envio de soldados brasileiros para a guerra na Coréia, suscitaram um clima favorável à identificação da ideologia comunista em setores do seu governo, principalmente no Ministério do Trabalho, cujo titular, João Goulart, cobrava novos direitos para os trabalhadores e reajuste do salário mínimo, contrariando, assim, amplo espectro formado por políticos, setores comercial e industrial, banqueiros e militares, que, afinal, obtiveram a sua destituição e a anuência de Vargas, que buscava se compor com os militares, para a instalação de inquéritos policiais militares (IPMs) que identificassem infiltração comunista nas Forças Armadas (Cf. Tavares, 2001).

No período 1950-1954, será a vez do SPI, após sérios reveses, buscar superar a imagem negativa que havia construído, malgrado o esforço de muitos, através da ação enérgica de José Maria da Gama Malcher. Ele substituiu os agentes recrutados sem as necessárias qualificações por etnólogos e indigenistas, aos quais atribuiu as principais divisões do órgão, procurando, desse modo, imprimir-lhe uma feição moderna, o que, de fato, consegue até 1955, quando o órgão é utilizado, à semelhança do que ocorreu com outros, como barganha política para os partidos políticos vitoriosos nas eleições de 1955.

Em maio de 1951, a pequena aldeia de Bom Jardim, agora mais correntemente denominada Barra Velha, se tornaria assunto jornalístico, devido a um movimento de sublevação, ainda hoje cercado de obscuridade, no qual foram envolvidos os Pataxó. O motim, desencadeado no vizinho povoado de Corumbau, suscitou uma desproporcional reação policial, que, além de danos físicos e emocionais, provocou a desorganização da população aí estabelecida. A "revolta dos caboclos de Porto Seguro" (A Tarde, 30/05/1951) revelou a existência de pessoas em "lastimável estado de miséria, todos passando fome e alguns doen- 
tes" (30/05/1951), que teriam sido insuflados por dois indivíduos que o capitão da época conhecera no Rio de Janeiro, e que lhe teriam prometido dirigir-se à aldeia para realizar a medição de suas terras. Os dois, identificados como "engenheiro" e "tenente" (A Tarde, 08/06/1951), pretextando ser isso necessário para a consecução de seus objetivos, indispuseram os índios contra a população não-índia dos arredores, notadamente a de Corumbau, onde teve lugar um assalto a um comerciante. Da dura repressão resultou a morte dos dois líderes não-índios, a prisão do “capitão" e de mais dez índios, homens e mulheres, e a dispersão dos demais, sob completo desespero. Quase que simultaneamente, noticiava-se uma tentativa de rebelião em Umburanas, Minas Gerais, para onde teria tentado deslocar-se "um grupo de 4 indivíduos" de Barra Velha (A Tarde, 28/05/1951), caracterizando a imprensa os dois movimentos como idênticos e sugerindo uma ligação entre eles. As evidências autorizam supor que não havia nenhum movimento em Umburanas, mas tão somente que para lá apelou o capitão Honório, tal como sugere a sua declaração de que mandara "cinco índios pedir auxílio aos cabocos do aldeiamento de Emburanas", ou seja, os amigos Maxakali ${ }^{6}$ (28/05/1951).

Essa suposição foi fortemente apoiada, muitos anos depois do "fogo de 1951" - como é referido pelos Pataxó o fato ocorrido em 1951 -, pelo pajé Albino Braz, que relatou que o capitão Honório, antes da repressão policial, havia enviado quatro índios a Umburanas para "pedir reforço", e que eles foram interceptados pela polícia. Até essa época, ocorriam contatos, mais ou menos regulares, entre os Maxakali e os Pataxó de Barra Velha:

o capitão ía lá na aldeia de Umburuna e de lá o capitão vinha na aldeia [de Barra Velha]. Lá já era viva, conhecida, e aqui não era. Então era o caso deles virem pra conversar com a gente da Aldeia de Barra Velha. Vinha de lá pra cá, caçando, e quando chegava aqui, trazia uma anta moqueada, uma queixada, trocava com o cacique, que dava rapadura, farinha, mandioca pra

${ }^{6}$ As relações entre os Pataxó e Maxakali são históricas, como o comprovam certas afinidades linguísticas e culturais. eles. Naquele tempo era mata, entrava nessa região aqui e ia sair em Maxakali.

Absolutamente improvável é a suposição de que o capitão Honório houvesse "previamente organizado o traiçoeiro ataque, estando apenas à espera de dois elementos do Rio de Janeiro conforme depõem alguns caboclos que se acham prisioneiros" (A Tarde, 01/06/1951). O próprio municiamento do grupo para a revolta - "espingardas de carregar pela boca, facas e facões" - ou seja, seus instrumentos de trabalho, demonstra a ausência de um plano sistemático de ação, pelo menos da parte dos índios. A declaração do "capitão" de que consentira aos "índios e seus parentes seguirem a orientação dos dois atacantes estranhos em virtude de acreditar que os mesmos procediam como agentes do governo" (A Tarde, 07/06/1951) atesta que os índios foram envolvidos possivelmente com promessas de demarcação de terras, e que sua participação não se lhes afigurara ilegal. Quanto à motivação dos dois insufladores - indivíduos que se apresentavam com falsa identidade e seriam ligados ao Partido Comunista, ${ }^{7}$ um deles tendo sido identificado pelo comandante da operação policial, major Arsênio Alves, como Ari Bhering - ainda hoje não está esclarecida. Há também quem os identifique como funcionários do SPI. Pouco provável, por outro lado, é que fossem simples aventureiros, arriscando-se à deflagração de um plano com objetivos de exploração econômica, e é mais plausível que se tratasse de um movimento de caráter social agindo junto a populações rurais. Em apoio a essa última hipótese há o depoimento de Honório Borges, que afirma ter o "engenheiro" distribuído entre os índios peças de

${ }^{7}$ Vale lembrar que o pedido de auxílio de Honório Rodrigues, em setembro de 1949, procede de Niteroi, onde, vinte e sete anos antes, portanto em 1922, havia sido fundado o Partido Comunista Brasileiro, por nove delegados que representavam cerca de 73 militantes de diferentes regióes do Brasil. Desarticulado durante o Estado Novo, ele se reorganiza, clandestinamente, em fins de 1941, através de grupos isolados do Rio de Janeiro, São Paulo e Bahia. Após um período de legalidade, o registro do Partido é cancelado pelo TSE, em abril de 1947, sob o argumento de ser "um instrumento da intervenção soviética no país", o que o deixou na clandestinidade (www.cpdoc.fgv.br). De todo modo, a relação do "fogo de 1951" com o PCB é apenas, até o momento, uma hipótese que requer comprovação cuidadosa. 
fazendas retiradas do estabelecimento comercial de Teodomiro Rodrigues, em Corumbau. O fato, ademais, de terem sido cortados os fios da linha telegráfica, corrobora a suposição de que não se trataria de um simples assalto, seguido da fuga e morte dos líderes, mas de uma ação que pretendia maior alcance.

Da parte da alta hierarquia do SPI, a reação diante da tramitação do processo 4073/49 foi, aparentemente, enérgica. José Maria da Gama Malcher, diretor do órgão em julho de 1951, encaminha o processo à I.R. 4, para que o seu Chefe indique um servidor capaz de

apurar por meios sumários as tropelias (confusão provocada por gente em tropel; ação que se vale de astúcia; ardil, artimanha, Cf. Dicionário Eletrônico Houaiss da Língua Portuguesa) cometidas contra os índios. Raimundo Dantas Carneiro, chefe da IR 4, refere-se também a tropelias e "complicada trama" (SPI, 1949).

O que teria ensejado que o processo formado a partir da singela carta do capitão Honório Borges permanecesse extraviado, aparentemente no âmbito do SPI, ao longo de um ano e dez meses? Aparentemente, houve intervenção para que a desprotegida Aldeia de Barra Velha não se tornasse objeto de atenção do órgão, o que, por outro lado, teria facilitado a ação dos dois agentes e produzido os consequentes fatos. As motivações permanecem, contudo, obscuras.

Curiosamente, no mesmo ano de 1951, na área dos Xacriabá, município de São João das Missões, norte de Minas Gerais, ocorrem fatos, igualmente obscuros, que podem ter conexão com aqueles sucedidos entre os Pataxó. Ademais, a história da relação dos dois povos com instâncias do Estado brasileiro guarda certa similaridade, uma vez que a primeira intervenção de um órgão federal na área Xakriabá resultou de uma segunda viagem dos índios "em algum momento entre 1930 e 1950" (Santos, 1997, p.60), tendo resultado na presença de um suposto antigo funcionário do SPI, Lyrio do Valle, que se autoconclamava "Cacique dos Índios de São João das Missões”, título que lhe teria sido outorgado por Rondon. Valle declarava haver sido enviado, em 1950, para São João das Mis- sões, com o objetivo de impedir os invasores de dominarem as terras dos Xacriabá. Ele teria exercido, anteriormente, os cargos de Delegado do SPI no Estado do Pará (1930), de capataz da caça e da pesca (1934), e Capitão da Missão Rondon em Mato Grosso (década de quarenta, possivelmente) (Valle, 1973 apud Santos 1997, p.59).

Um delegado especial, oriundo de Belo Horizonte, foi enviado a São João das Missões em 1951, para efetuar a prisão de Lyrio do Valle e seu filho, ação para a qual teriam também se deslocado membros dos destacamentos militares de Montes Claros, Januária, Itacarambi, Manga, além do próprio destacamento de Matias Cardoso (Santos, 1997, p.62). Os documentos pessoais de Valle foram apreendidos, entre os quais a escritura das terras de São João das Missões e um mapa com a demarcação dos limites. Transferidos para Belo Horizonte, permaneceram na Penitenciária de Ribeirão das Neves, incomunicáveis, após o que foram levados para a Secretaria do Interior - Departamento de Identificação - e interrogados separadamente. Retornaram para a Casa de Correção, de onde seriam liberados pouco depois, por ordem de Getúlio Vargas, que soube dos acontecimentos pelo seu secretário Lourival Fontes, acionado pela esposa de Valle. Esse último viajou para o Rio de Janeiro, de avião, onde teria recebido nova documentação de José Maria Gama Malcher como "Índio e como capitão do Serviço de Proteção aos Índios e cacique dos Índios de várias tribos", e foi, em seguida, reconduzido, triunfalmente, a Manga (1997, p.63).

Ao tomarem conhecimento da sua prisão e do filho, os índios ficaram amedrontados e alguns até fugiram (p.65). Santos observa ainda que os índios Xacriabá se referiram, em uma das cinco conversas em que o tema foi comentado, a reuniões que Valle organizou.

Uma conexão entre o "fogo de 1951" e os acontecimentos de São João das Missões é estabelecida pelo Jornal A Tarde, ao chamar a atenção do leitor para "idêntica rebelião [que] acaba de se verificar no interior de Minas Gerais)" (A Tarde, 29/05/1951). 


\section{A Luta pelo reconhecimento}

O destino de Honório após 1951 não é muito preciso. As poucas evidências levam a supor que ele foi submetido ao ostracismo. $\mathrm{O}$ atual pajé da aldeia de Boca da Mata, o já referido Manuel Santana, por exemplo, indagado sobre o seu paradeiro, respondeu, evasivamente, que ele "sumiu, foi embora, desapareceu", referindo-se, na sequência, ao novo capitão, Epifânio Ferreira, "que resolveu o problema pra gente”. Epifânio e dois dos seus filhos viajaram para Brasília, "de onde trouxe o direito da gente viver aqui dentro da aldeia”, direito que teria sido concedido pelo presidente João Goulart, o que permite deduzir que a viagem transcorreu entre o final de 1961 e o início de 1964. Com o retorno de Epifânio, sinal positivo foi emitido para os pataxós que estavam ainda dispersos, e que foram encorajados pelo novo capitão a abrir novas roças na capoeira, "pra não ofender a mata virgem", segundo o que recomendara o presidente Goulart.

A administração do PNMP resistia, mediante o exercício da violência, física e simbólica, ao estabelecimento de roças, em face do que muitos conflitos ocorreram. As pequenas roças eram complementadas com a pesca nos arrecifes, a coleta no mangue e a extração de piaçava às escondidas, nas primeiras horas do dia, para ser transportada, na primeira parte da noite, para Caraíva, onde era comercializada. O cotidiano alternava-se entre "redar [pescar com rede] uma semana, pegar o peixe pra comprar farinha, e outra semana ia tirar piaçava e as mulher fundava no mangue pra tirar o caranguejo. Ficamo um bocado de ano assim desse jeito...”

O fogo de 1951 é também mais ou menos recorrentemente apontado como fator motivador da "mistura", ou seja, da intensificação de alianças interétnicas com não-índios. Nesse sentido, a afirmação de que "até o fogo, a mistura era pouquinha” é consensual. Na década de setenta, a admitida mistura, decorrente da compulsória dispersão e consequente desorganização das relações sociais - "Iam conhecendo outros lá fora, ia casan- do índio com outra nação" -, era encarada muito negativamente pelos mais velhos, para quem "misturando vai acabando a nação”. De acordo com a sua percepção, nenhuma mudança repercutia tão desfavoravelmente sobre a nação Pataxó quanto a mistura, que ameaçava a sua persistência. "E não tendo mistura, a nação tem que conseguir", era a sua conclusão axiomática.

A dispersão resultante dos distúrbios igualmente ensejou, em decorrência do abandono provisório da Aldeia de Barra Velha, a reocupação de porções do território tradicional e a ocupação de novas, a exemplo de Corumbauzinho; de Mata Medonha, implantada em 1951 por uma família de refugiados de Barra Velha, à qual se acrescentariam outras, nos anos oitenta; de Águas Belas, consolidada, também na década de oitenta por migrantes de Barra Velha não-retornados; do mesmo modo que a velha Aldeia de Imbiriba, que teve a sua população incrementada após 1951. Coroa Vermelha foi igualmente produto da grande diáspora Pataxó. Cada aldeia, vale notar, reportase a uma família extensa, considerada desbravadora do local. ${ }^{8}$ Costuma-se fazer referência aos Braz como estabelecidos nos arredores de Barra Velha - "Anjo", "Onça" e "Boa Vista" - oriundos que seriam de Belmonte, do mesmo modo que o "pessoal de Nazaro". Já os Valério são referidos como vivendo, tradicionalmente, parte em Caraíva e parte em Juacema, de onde, majoritariamente, se teriam deslocado para a Coroa Vermelha. Barra Velha teria estreita relação com os chamados troncos de João Vicente, que de Imbiriba se teriam deslocado para essa aldeia, como atesta o fato de que os velhos de Imbiriba eram tios dos velhos de Barra Velha, Vicente, Vicentinho e Epifânio Ferreira. Trancoso é reputada ser aldeia dos Alves. ${ }^{9} \mathrm{E}$

3 Os Pataxó estão hoje distribuídos em 18 aldeias, cujas populações variam entre 4.331 habitantes (Coroa Vermelha, a mais populosa), 1.650 habitantes (Barra Velha, a denominada aldeia-mãe e segunda mais populosa) e 62 habitantes (Alegria Nova, formada após a retomada do Parque). As 18 aldeias incidem nos municípios de Porto Seguro, Itamaraju e Santa Cruz Cabrália e compreendem 10.192 habitantes (FUNASA-SIASI, 2008) (V. Mapa).

${ }^{9} \mathrm{O}$ reconhecimento de que os Alves são originários de Trancoso, aldeia indígena desbaratada no final da década de setenta do século XIX, suscita a possibilidade de serem eles índios do tronco Tupi, que se teriam refugiado 
Palmares, ao sul, dos Pires, que são constantemente referidos, e muito respeitados, por nunca terem se retirado do local.

Em 1963, o SPI tenta sensibilizar a direção do PNMP para que os Pataxó permaneçam em suas terras. Um telegrama, procedente do Ministério da Agricultura, Serviço de Proteção aos Índios, cujo signatário é Francisco Sampaio, Chefe de Serviço de Índios, é dirigido ao Diretor do Parque Nacional em Porto Seguro-BA, com o seguinte teor:

Informado pelo Sr. Prefeito dessa cidade estarem os Índios Pataxó impossibilitados lavrarem suas terras absorvidas pelo Parque Nacional sob vossa direção, venho apelar para vosso espírito de justiça, permitindo que os Índios continuem cultivando a área que for necessária à sua subsistência. Este apelo tem por fim evitar que venham sofrer privações por falta das terras que inapelavelmente lhes pertenciam e por coincidência no ponto exato em que se deu o nosso descobrimento. Confiado no vosso patriotismo espero ser atendido" $\left(\mathrm{Ms}^{(4)}\right)$.

Em 25 de março de 1964, Sampaio estabeleceu contato direto, em Salvador, com Aurélio Costa, o Doutor Barros, Chefe da $4^{\mathrm{a}}$. Inspetoria do Serviço Florestal da Bahia, à qual estava subordinado o PNMP, apresentando-lhe a denúncia de que os Pataxó se encontravam "perseguidos e privados de trabalhar nas terras em que nasceram, pelos funcionários do Parque (Ms $\left.{ }^{(5)}\right)$, ênfases adicionadas). Costa elaborou um cartão, dirigido a Miravaldo de Jesus Siquara, chefe-provisório do Parque Nacional, autorizando-o a combinar com Sampaio "uma fórmula que permitisse aos Índios o direito de trabalhar no cultivo das terras" $\left(\mathrm{Ms}^{(5)}\right)$.

De Salvador, Sampaio seguiu para Porto Seguro, onde fez contato com o prefeito local, após o que alcançou Caraíva, e, na sequência, a Aldeia de Barra Velha, por essa época reduzida a duas casas e uma igrejinha, pois "o resto da população indígena vive esparsa” $\left(\mathrm{Ms}^{(5)}\right)$. A notícia da pre-

entre os Pataxó do extremo-sul, ao passo que outros, da mesma aldeia, teriam se dirigido para o sul da Bahia, onde Curt Nimuendaju os encontrou em 1938 (Carvalho, 2005). A composição étnica das aldeias dos Pataxó do extremo-sul (que os etnólogos convencionaram designar Pataxó meridionais), do mesmo modo que a dos Pataxó do sul (Pataxó setentionais), constitui tema fascinante, que já está sendo objeto da minha atenção. sença de Sampaio atrairia grande número dos dispersos, que, reunidos, queixaram-se "de estar privados de trabalhar e de sofrerem outros aborrecimentos por parte dos guardas florestais, que os impedem de viver agrupados como desejam.” $\left(\mathrm{Ms}^{(5)}\right)$.

Siquara estava ausente, o que impediu que Sampaio lhe fizesse pessoalmente a entrega do cartão encaminhado por Costa. Na viagem de volta, o inspetor adquire, em Porto Seguro, ferramentas, inseticidas, anzóis, cobertores, tecidos e medicamentos, encarregando o subdelegado de distribuílos entre os Pataxó. Previdente, detém-se, mais uma vez, em Salvador, para participar a Costa as providências tomadas, reiterar-lhe o direito, por parte dos Pataxó, ao trabalho e permanência "nas terras de seus ancestrais”, e apresentar-lhe já uma proposta mínima de terras a ser reservada para os índios, ou seja, "um quadrilátero de 900 hectares" ${ }^{10}\left(\mathrm{Ms}^{(5)}\right)$.

A visita de Francisco Sampaio causou forte impressão aos Pataxó e, mais uma vez, constitui demonstração da sua poderosa memória. Desde 1976 ouço referências a Sampaio, apontado como “o primeiro [provavelmente agente governamental] que andou aqui”. A sua visita é diretamente relacionada à viagem de Epifânio Ferreira a Brasília, e não guarda conexão, entre os índios, com os fatos relacionados à viagem de Honório Borges ao Rio de Janeiro, em 1949. Resoluto, Sampaio produziu, em sua curta estadia, uma imagem muito positiva de provedor e de assegurador do direito dos Pataxó ao trabalho, cujo efeito foi o início do retorno dos dispersos.

Em junho de 2004, tomei a iniciativa, após várias tentativas para localizar Miravaldo Siquara, de visitá-lo e entrevistá-lo em Alcobaça, extremosul baiano, onde reside. Muito loquaz e receptivo, recebeu-me muito calorosamente. Aposentado e levando uma vida pacata, aparentemente muito diferente daquela vivenciada como chefe do PNMP,

\footnotetext{
${ }^{10}$ A área reservada em 1965 foi muito menor do que aquela reivindicada por Sampaio, ou seja, apenas 210 ha em torno de Barra Velha (IBDF, 1979). Igualmente foi acolhida a sua recomendação de criação de um Posto Indígena, implantado em 1968. Ao longo desse período, os Pataxó enfrentaram, com determinação e coragem, os guardas do Parque.
} 
ele deve ter ficado lisonjeado com o meu interesse em entrevistá-lo. Ele se reportou a 1956, ano da criação da Polícia Florestal, quando participou de um curso preparatório para inspetor, após o que foi designado inspetor da região do extremo-sul baiano. Em 1960, foi convocado por Aurélio Costa para acompanhar a comissão composta pelo próprio Costa e mais dois membros, designada para proceder à recriação do PNMP, uma vez que o primeiro decreto caducara sem que o governo federal tomasse as medidas efetivas para a sua implementação, em face do que as terras doadas pelo Estado da Bahia reverteram ao seu controle. O seu relato autoriza concluir que ele foi, com exagerado rigor, o verdadeiro artífice da desocupação da população indígena que habitava nos limites compreendidos pelo PNMP e da população nãoindígena, genericamente referida como capixaba, que, crescentemente, forçava a entrada. Recebia as ordens de desocupação, provenientes de Barros, e as executava com excessivo zelo. Os seus esforços resultaram no decreto $\mathrm{n}^{\circ} 242$ de 29 de novembro de 1961, que criou o Parque Nacional do Monte Pascoal com a área de 22.500 hectares. ${ }^{11}$

Ao ser finalizado, sob a liderança de Siquara, o levantamento realizado abruptamente, para efeito das indenizações, todas as atividades produtivas foram terminantemente proibidas ("Ninguém caçava, ninguém fazia mais nada. Proibe tudo!"). Consultado sobre o destino dos Pataxó, Costa sugeriu limitar uma área de mais ou menos 100 hectares e "deixar os índios fazerem uma barraquinha e ficar ali até que se resolva o problema. Agora, eles não podem plantar nada que não seja cereal, não consinto! Agora o resto, deixe eles lá trabalhando até que o SPI resolva o que é que faz com eles".

Um acordo entre a FUNAI e o IBDF-aparen-

${ }^{11}$ O leitor, muito provavelmente, não seria capaz, por si só, de identificar o autor da afirmação que segue: "Por seu isolamento e pequena expressividade, essa aldeia sequer foi mencionada no decreto de criação do Parque Nacional de Monte Pascoal. Os índios, que antes podiam desfrutar de toda a região compreendida entre os rios Corumbau e Cemitério, do Monte Pascoal até o oceano Atlântico, num raio de aproximadamente $50 \mathrm{~km}$, ficaram confinados em uma área de cerca de 210 hectares, com terras consideradas de baixíssima fertilidade" (IBAMA, 1995, p.12). temente acompanhado e corroborado, por parte dos Pataxó, apenas pelo cacique e vice-cacique à época, (respectivamente, Rufino Vicente Ferreira e Alfredo Braz)-foi celebrado em 1980. OIBDF admitiu que o correspondente à metade norte da área, identificada como território de ocupação tradicional Pataxó, predominantemente composta por brejos arenosos junto ao estuário do Caraíva, passasse ao seu usufruto, permanecendo, porém, os manguezais junto ao estuário do rio Corumbau - fonte de proteína animal especialmente relevante para a sua dieta - sob controle do PNMP (Sampaio, 1996).

Em que pese o caráter lesivo e sem consulta ampla aos Pataxó, aos antropólogos e indigenistas que vinham se dedicando à questão (Carvalho, 1987), a área resultante da combinação FUNAI/IBDF - 8.627 hectares - foi submetida à apreciação do Grupo de Trabalho Interministerial criado pelo Decreto 94.945/87 que, em sua Resolução 02, de 20 de julho de 1988, resolveu "reconhecer" a área como "de posse imemorial indígena", recomendando sua regularização com a designação "Colônia Indígena Barra Velha". Por fim, ela foi homologada pelo Decreto 396 (24/12/91) da Presidência da República (FUNAI, 1991; Sampaio, 1996).

O descontentamento e a frustração causados pela demarcação de 1980 foram muito grandes entre os Pataxó. Testemunhei muitas queixas e lamentos, expressos sob intenso sofrimento. Eu não hesitaria em afirmar que Paulo Braz, mais conhecido como Paulo Baraúna, deixou-se morrer de desgosto por essa mal sucedida demarcação. Normalmente tenso, o que lhe conferia um temperamento agitado, que disfarçava a sua delicadeza, Paulo tinha problemas cardíacos e havia perdido, em um acidente, um dos antebraços. A sua ligação com a terra era profunda e, em geral, objeto de uma preocupação quase obsessiva. Em 9 de dezembro de 1980, ele e mais dois signatários, Benedito Ferreira Braz e José Farias do Nascimento, encaminharam ao Presidente da República, João Figueiredo, uma carta, na qual rejeitam a demarcação "porque essa área não dá pra nós sobreviver dentro dela, a metade desta sendo de areia branca, campo nativo, brejo e lagoa. Pedimos ao senhor 
que nos dê um apoio sobre esse assunto da terra, nós somos uma comunidade de mais de 1.000 pessoas e essa terra, mal medida como foi, não dá pra nós e nossos filhos. Dessa forma, dentro de pouco tempo não haverá mais a nação Pataxó, nós índios morremos de desgosto e de fome (ANAI, 1980). Paulo Baraúna faleceu em 1987.

Transcorre um longo intervalo, no decorrer do qual os Pataxó se mobilizaram, de diversos modos, sempre tendo em vista a reconquista da área do PNMP. Avanços significativos no âmbito da sua organização social e política foram produzidos, para o que muito concorreram as assembléias indígenas, internas e externas, a formação de novos líderes, com maior domínio do aparelho burocrático, um processo crescente de escolarização e a criação da Articulação dos Povos e Organizações Indígenas do Nordeste, Minas Gerais e Espírito Santo (APOINME). Sob o estímulo da APOINME, surge o Conselho de Caciques do Sul e Extremo-Sul da Bahia, que passa a articular e planejar o movimento regional, em progressiva conexão com o movimento indígena suprarregional.

No período compreendido entre 16 e 19 de agosto de 1999, representantes das aldeias Pataxó, reunidos em uma assembléia do Conselho de Caciques, confirmaram a necessidade de ampliação e recuperação do território tradicional, e, em Carta às autoridades brasileiras, afirmaram que:

... conscientes de que o Parque Nacional está dentro dos limites de nossa terra, conforme a história de nossos anciãos, decidimos imediatamente RETOMAR o nosso território, neste dia 19 de agosto de 1999, protegidos pela memória dos antepassados, protegidos pelo direito constitucional [...] pretendemos transformar o que as autoridades chamam de Parque Nacional do Monte Pascoal em Parque Indígena, terra dos Pataxó, para preservá-lo e recuperá-lo da situação que hoje o governo deixou a nossa terra, depois de anos na mão do IBDF, atual IBAMA, que nada fez a não ser reprimir os índios e desrespeitar nossos direitos. Queremos deixar claro para a sociedade brasileira, para os ambientalistas, para as demais autoridades que não somos destruidores da floresta, como tem sido proclamado [...] Vamos celebrar os 500 anos em nossa terra, receberemos os nossos parentes de todo o Brasil aqui, no Monte Pascoal, único local possível para construirmos o futuro com dignidade. [...] Mais uma vez pedimos o apoio de toda a sociedade brasileira (Carta do Povo Pataxó, 1999).

Visitei o Parque poucos dias depois da retomada e testemunhei o ânimo e a disposição favoráveis por parte de vários caciques e seus liderados. Ao mesmo tempo, registrei várias referências ao falecido capitão Epifânio Ferreira, concernentes ao mesmo tema, isto é, o da sua intercessão pelo direito ao território Pataxó: “ele sempre diz para o pessoal dele que está no pé do governo, cobrando os direitos da terra, os direitos dos parentes, os direitos de nós. Ele encosta ${ }^{12}$ nos parentes e fala, em sonho. Está na luta da terra ainda!"

Comentar-se-ia, tempos depois, que, na primeira festa ocorrida no chamado Pé-do-Monte, local do antigo posto, Epifânio "encostou” na filha Josefa e declarou que "só descansaria quando ganhasse a terra toda, da beira da praia à Serra da Gaturama”. Em uma das inúmeras vezes em que o fato foi comentado em minha presença, uma pataxó, completou, firmemente: "tá perto dele descansar". A recuperação do Parque havia recobrado a autoestima e a confiança dos Pataxó, e os impeliria a realizar sucessivas retomadas de porções do território, de onde foram, em distintos períodos históricos, expelidos.

O sentimento de injustiça por eles vivenciado parece haver funcionado como um impulsionador de ações coletivas que produziram expectativas de reconhecimento, crescentemente revertidas em seu benefício. Não é casual que a reconquista do núcleo do seu tradicional território tenha ocorrido a poucos meses da rememoração do ato do qual se originaria o Estado e a nação brasileiros, assim como não o foi a sua proclamação - às autoridades brasileiras, à sociedade brasileira - da decisão de retomar o território, protegidos pela memória dos antepassados e pelo direito constitucional. De fato, em 1998, o Conselho de Caciques, no decorrer de uma reunião de planejamento, havia definido uma agenda de retomadas, entre as quais a do PNMP. Expressava-se, ali,

\footnotetext{
12 "Encosto" é uma manifestação dos espíritos dos mortos que se tornam encantados. Para os Pataxó, "toda quanta é tribo tem encantado. Porque todos índio que morre eles sempre vem visitar a aldeia deles“.
} 
uma nova comunidade político-moral, forjada contemporaneamente, ao longo das vicissitudes decorrentes da viagem de Honório Borges ao Rio de Janeiro e fortalecida, mais recentemente, através do apoio político de várias organizações indígenas e indigenistas. Uma nova etapa havia sido vencida enquanto outras já se anunciavam, agora orientadas para a demarcação contínua do território tradicional, contra a qual têm se interposto, não sem violência física e simbólica, os interesses de novos atores sociais, tais como fazendeiros, empresas do setor de turismo e a VERACEL Celulose.

Eu suponho, finalmente, ter conseguido desvelar, ao longo do texto, um nexo objetivo-intencional entre os eventos relatados, que já não figurariam como meros eventos, mas como etapas em um processo de formação conflituoso, conduzindo a uma ampliação crescente das relações de reconhecimento (Honneth 2003, p.268). Suponho ainda que, ao tratar da relação entre condições de vida, deslocamento espacial e direitos do povo indígena Pataxó, tenha atendido aos objetivos da proposta elaborada pela organizadora do Dossiê. Mas ao leitor caberá decidir se, de fato, o percurso utilizado e as hipóteses e formulações desenvolvidas estão suficientemente validadas pelas evidências apresentadas.

(Recebido para publicação em julho de 2009) (Aceito em setembro de 2009)

\section{FONTES PRIMÁRIAS - MANUSCRITOS}

Seção Republicana Cx. 2083 e 2084. Maço 2466. Bahia, 23.10.1940. Lafaiete Ponde, secretario de Interior e Justiça, encaminha telegrama ao Prefeito de Porto Seguro renovando recomendações sobre cobrança impostos madeiras. $\left(\mathrm{Ms}^{(1)}\right)$

Secção Republicana /Secretaria de Governo. Cx. 2090 Maço 2481 Em 04.05.41, a Delegacia Regional (Bahia) de Recenseamento, através do Delegado Regional Ruben Gueiros, envia congratulações pela assinatura decreto 11.892 constituindo comissão levantamento topográfico Monte Pascoal, publicado Diário Oficial de hoje $\left(\mathrm{Ms}^{(2)}\right)$

CONSELHO ULTRAMARINO BRASIL - Bahia. Representação do padre Cypriano Lobato Mendes dirigida a D. Pedro III, sobre a situação econômica da Capitania da Bahia, em que se contêm noticias muito interessantes. Bahia, 31 de julho de 1788 . $\left(\mathrm{Ms}^{(3)}\right)$
MINISTÉRIO DA AGRICULTURA/SPI. Telegrama de Francisco Sampaio, Chefe de Serviço de Índios, ao Diretor do Parque Nacional, em Porto Seguro-BA, 4.08.1963. $\left(\mathrm{Ms}^{(4)}\right)$

SPI. Francisco Sampaio, Inspetor do SPI, dirige-se a um Diretor.do órgão, em 6. 05. 64, para relatar o cumprimento da ordem de serviço no. 32 , de 25 de março do mesmo ano. 6. 05. $64\left(\mathrm{Ms}^{(5)}\right)$.

\section{REFERÊNCIAS}

ANAI. Carta de Índios Pataxó ao Presidente da República, João Figueiredo. Brasília,DF: 1980. (Digit.)

A TARDE. Salvador, 28; 29; 30 maio 1951. Salvador, 06; 07; 08 jun., 1951.

BAHIA. Decreto $\mathrm{n}^{\circ} 11.892$ de 2 de maio de 1941 . Constitue uma Comissão Especial a fim de fazer o levantamento topográfico do Monte Pascoal. Palácio do Governo do Estado da Bahia, em 2 de maio de 1941. Landulpho Alves, Interventor Federal - Lafayette Pondé - Isaías Alves Delsue Moscoso.

Decreto-Lei nº12.729 de 19 de abril de 1943. Cria o Parque Nacional do Monte Pascoal com prerrogativas de monumento nacional e dá outras providências. Diário Oficial, 19 abr., 1943

BUONICORE, Augusto. Os comunistas, os índios e a nação. Vermelho. Disponível em: www.vermelho.org.br Acesso em: 28 maio 2009.

CARVALHO, Maria Rosário de. Os Pataxó de Barra Velha seu subsistem econômico. 1977. 436 f. Dissertação (Mestrado em Ciências Humanas) - Programa de PósGraduação em Ciências Humanas da Universidade Federal da Bahia. Salvador, 1977.

Índios do Sul e Extremo-Sul Baianos: reprodução demográfica e relações interétnicas. Caderno CRH: Centro de Recursos Humanos da UFBA, Salvador, n.43, p.35-55, jan./abr. 2005

Os Pataxó meridionais (Porto Seguro/Bahia): considerações sobre a demarcação realizada em 1980. In: SILVA, José Luis Caetano da (Org). Tradições étnicas entre os Pataxó no Monte Pascoal: subsídios para uma educação diferenciada e práticas sustentáveis. Vitória da Conquista,BA: Núcleo de Estudos em Comunicação, Culturas e Sociedades. NECCSos, 2008. p.393-402. (Edições UESB)

CASTRO, R. Berbert de (Org.). Sob os céus de Porto Seguro. Salvador: Diretoria de Cultura e Divulgação do Estado da Bahia; Imprensa Oficial do Estado, 1940.

CARTA do Povo Pataxó às autoridades brasileiras. Aldeia de Monte Pascoal/Porto Seguro 19 de agosto de 1999.

COLEÇÃO La Correspondencia Sudamericana - Órgão Oficial do Secretariado Sul-Americano da Internacional Comunista - 1929-1930.

DAS, Veena. Critical events: an anthropological perspective on contemporary India. New Delhi: Oxford University Press, 1995.

DENNIS, Ferdinand. Brasil. Belo Horizonte: Itatiaia; S. Paulo: EDUSP, [1838]1980.

FERREIRA, John Kennedy. I Conferência dos Partidos Comunistas da América Latina: a questão indígena formulada por José Carlos Mariátegui. Revista Espaço Acadêmico, Maringá,PR, v.8, n.92, jan., 2009. Disponível em: REA 092 On-Line. Acesso em: 28 maio 2009. 
FUNAI. Decreto no396/91 Homologa a demarcação administrativa da Área Indígena Barra Velha, no Estado da Bahia. (Fernando Collor/Jarbas Passarinho). 24 dez., 1991.

IBAMA-BA. Plano de Ação Emergencial para o Parque Nacional de Monte Pascoal. Documento Final, 1995. (Digit.)

IBDF. Plano de Manejo do Parque Nacional de Monte Pascoal. 1979. 133 p.

HONNETH, Axel. Luta por reconhecimento: a gramática moral dos conflitos sociais. São Paulo: Ed. 34, 2003.

HOBSBAWM, Eric. J. Nações e nacionalismo desde 1780 Rio de Janeiro: Paz e Terra, 1990.

MINISTÉRIO DO INTERIOR/Fundação Nacional do Índio. Memória In: FUNAI, 14 jun. 1984, Barra Velha,BA. Reunião. Participantes Comunidade Indígena Pataxó. IBDF, 1984. (Dat.)

MONTI, Ednardo Monteiro Gonzaga do. Canto orfeônico: os ideais cantados do Estado Novo. Travessias, Cascavel,PR, n.2, p.1-16, 2007.

PRESIDÊNCIA DA REPÚBLICA. Casa Civil/Subchefia para Assuntos Jurídicos. Constituição dos Estados Unidos do Brasil, de 10 de novembro de 1937.

SAMPAIO, J.A. Laranjeiras. Breve história da presença indígena no extremo-sul baiano e a questão do território Pataxó do Monte Pascoal. Penedo, 1996. (Digit.)
SANTOS, Ana Flávia Moreira. Do terreno dos caboclos do Sr. São João à Terra Indígena Xakriabá: as circunstâncias da formação de um povo. Um estudo sobre a construção social de fronteiras. 1997. 350 f. Dissertação (Mestrado em Antropologia) - Programa de Pós-Graduação em Antropologia Social da Universidade de Brasília. 1997.

SPI. Processos nº4073/49 e 619/51 I.R. 1949. Cópia $A u-$ têntica do Processo referente aos Indios da Aldeia Velha, Monte Pascoal, Município de Porto Seguro.

TAVARES, Luís H. Dias. História da Bahia. São Paulo: Ed. UNEP; Salvador: EDUFBA, 2001.

VALLE, Lyrio do. Depoimento do Cacique Lyrio do Valle: Chefe da Tribo dos Indios de São João das Missões Processo FUNAI/BSB nº4108/76, 1973, fls.330-335. (Relatório da Índia Tupi Luíza do Valle) Digit.

VASCONCELOS, Simão de. Chronica da Companhia de Jesus do Estado do Brasile no que obraram seus filhos nesta parte do Novo Mundo e algumas noticias antecedentes curiosas e necessárias das cousas daquelle Estado pelo padre Simão de Vasconcelos. 2. $^{\mathrm{a}}$ edição, accrescentada com uma introdução e notas históricas e geographicas pelo conego Dr. Joaquim Caetano Fernandes Pinheiro. Rio de Janeiro: Tipographia de João Ignácio da Silva. [1663]1864

VILHENA, Luis dos Santos. A Bahia no século XVIII. Salvador: Ed. Itapuã. [1759] 1969. Livro 2. 


\section{MONTE PASCOAL, THE PATAXÓ INDIANS AND THE FIGHT FOR ETHNIC RECOGNITION}

\section{Maria Rosário de Carvalho}

This paper treats of the struggle between the Pataxó Indians and the Brazilian State by the ownership of Mount Pascoal's National Park, for which are used the notion of critical events and the conflict model that attributes the appearance and the course of the social struggle to the moral experiences of the social groups in face of the denial of the recognition. The aim of this paper is to demonstrate, through the presentation of the several stages of the struggle, to demonstrate that the critical events related to the creation of PNMP (in English, Mount Pascoal National Park) while bringing serious contradictions for the Pataxó, collaborate to the genesis of a new political-moral community. The focus incides, therefore, in the interface between demography and anthropology, striving to relate living conditions, the space displacement and the rights of an indigenous people. KEYworDs: Pataxó, nation, recognition, struggle, monument.

\section{MONTE PASCOAL, LES INDIENS PATAXÓ ET LA LUTTE POUR UNE RECONNAISSANCE ETHNIQUE}

\section{Maria Rosário de Carvalho}

L'article traite de l'affrontement qui a eu lieu entre les Indiens Pataxó et l'Etat brésilien pour la possession du Parc National de Monte Pascoal. On y utilise la notion d'événements critiques et du modèle de conflit qui attribue le surgissement et l'avènement des luttes sociales à des expériences morales de groupes sociaux qui se trouvent face à un refus de reconnaissance. L'objectif est de démontrer, à partir de la présentation des différentes étapes de la lutte, que les événements critiques, liés à la création du PNMP, objet de graves contradictions pour les Pataxó, ont collaborés à l'origine d'une nouvelle communauté politique et morale. En effet, l'accent est mis sur l'interface démographique et anthropologique et cherche à faire le lien entre les conditions de vie, le déplacement dans l'espace et les droits d'un peuple indigène. Mots-CLÉs Pataxó, nation, reconnaissance, lutte,

Maria Rosário de Carvalho - Doutora em Antropologia Social pela Universidade de São Paulo (USP). Professora Associada I do Departamento de Antropologia e Etnologia e Professora Permanente do Programa de Pós-Graduação em Antropologia e do Programa Multidisciplinar em Estudos Étnicos e Africanos da UFBA. Publicou Os Kanamari da Amazônia Ocidental História, Mitologia, Ritual e Xamanismo. Salvador, BA: Fundação Casa de Jorge Amado, 2002, organizou Identidade Étnica, Mobilização política e Cidadania. Salvador, BA: Empresa Gráfica da Bahia, 1990, e produziu um conjunto de artigos e capítulos de livros. Coordena o Programa de Pesquisas sobre Povos Indígenas do Nordeste Brasileiro e é Bolsista PQ do CNPq. 
